S44 ORTHODEOXIA, AND POSTURAL ORTHOSTATIC TACHYCARDIA, IN 165 CONSECUTIVE, UNSELECTED PATIENTS WITH PULMONARY ARTERIOVENOUS MALFORMATIONS

V Santhirapala, JT Springett, H Wolfenden, HC Tighe, JE Jackson, CL Shovlin; Imperial College London, London, UK

\subsection{6/thoraxjnl-2013-204457.51}

Background Patients with pulmonary arteriovenous malformations are often quoted as displaying orthodeoxia, that is, a fall in oxygen saturation on standing. It is unclear how common this phenomenon is, and how patients would compensate for any acute fall in $\mathrm{SaO}_{2}$.

Methods Postural changes in oxygen saturation and pulse were examined in a series of 165 prospectively-recruited patients with radiologically-proven PAVMs. Self-reported exercise at presentation was graded using a modified MRC dyspnoea scale. $\mathrm{SaO}_{2}$ and pulse measurements were made in both erect and supine postures on 1-8 separate occasions through presentation to postembolisation follow up. These 522 sets of postural measurements displayed very high within-patient reproducibility.

Results Age ranged from 17-87 (median 49) ys, 62 (37.6\%) were male, and for 159 (96\%), PAVMs were attributable to HHT. 18.9\% were obese with a body mass index (BMI) $>30$, including one with morbid obesity $(\mathrm{BMI}>40)$. At presentation, the $\mathrm{SaO}_{2}$ fell by at least $2 \%$ on standing in $51(33 \%)$ patients, compared to the equivalent average supine reading. A smaller fall of 1-2\% was present in a further $28(17 \%)$ of patients. Patients with higher BMI had significantly higher supine $\mathrm{SaO}_{2}$ for their erect $\mathrm{SaO}_{2}$, and significantly lesser falls in $\mathrm{SaO}_{2}$ on standing. A postural tachycardia consistently exceeded the increment required to sustain oxygen delivery at rest, across all $\mathrm{SaO}_{2} .12 / 163$ (7.4\%) of individuals met the pulse definition for postural orthostatic tachycardia syndrome with an increase on standing of more than 30 beats per minute. Once adjusted for baseline supine pulse and age, the erect pulse was lower in patients with higher BMI (adjusted regression coefficient 0.23 (95\% confidence interval $0.026,0.48), \mathrm{p}=0.011$ ). Using the pre-specified 5 group grading system, exercise tolerance was worse in patients with lesser postural tachycardias (regression coefficient $-2.19(-3.74,-0.65) \mathrm{p}=0.006))$.

Conclusions Orthodeoxia and postural tachycardia are common in PAVM patients. More pronounced postural tachycardias were associated with improved exercise tolerance. Further studies will be required to assess if this is because it is a surrogate of lower $\mathrm{BMI}$, with obesity effectively limiting a further fall in $\mathrm{SaO}_{2}$ on standing because of obesity-related lower supine $\mathrm{SaO}_{2}$.

\section{S45 SPECIFIC VENTILATION INEQUALITY AND DEAD SPACE COMPONENTS OF LUNG CLEARANCE INDEX IN PATIENTS WITH ASTHMA AND CYSTIC FIBROSIS}

${ }^{1} S$ Gonem, ${ }^{1} S$ Natarajan, ${ }^{1} \mathrm{~A}$ Singapuri, ${ }^{1} \mathrm{Ce}$ Brightling, ${ }^{2} \mathrm{P}$ Gustafsson, ${ }^{3} \mathrm{~A}$ Horsley, ${ }^{1} S$ Siddiqui; ${ }^{1}$ Institute for Lung Health, University of Leicester, Leicester, UK; ${ }^{2}$ Department of Paediatrics, Central Hospital, Skövde, Sweden; ${ }^{3}$ Manchester Adult Cystic Fibrosis Centre, Manchester, UK

10.1136/thoraxjnl-2013-204457.52

Background Lung clearance index (LCI) is a widely reported marker of gas mixing inefficiency within the airways that is derived using the multiple breath inert gas washout (MBW) technique. We developed two novel parameters, $\mathrm{LCI}_{\mathrm{vent}}$ and $\mathrm{LCI}_{\mathrm{ds}}$, to reflect the components of increased LCI due to (i) unequal convective ventilation between relatively large lung units, and (ii) increased respiratory dead space, respectively. We hypothesised that these parameters would be repeatable, would effectively discriminate between healthy controls and patients with asthma and cystic fibrosis (CF), and would distinguish between different subphenotypes of these diseases.

Methods Washout data from sixty-six healthy control subjects, seventy-four patients with asthma, and forty-one patients with $\mathrm{CF}$ were fitted to a two-compartment model of gas mixing, and the parameters $\mathrm{LCI}_{\mathrm{vent}}$ and $\mathrm{LCI}_{\mathrm{ds}}$ were calculated.

Results $\mathrm{LCI}_{\mathrm{vent}}$ and $\mathrm{LCI}_{\mathrm{ds}}$ were markedly elevated in patients with CF, and mildly elevated in patients with asthma, compared to controls, as illustrated in Figure $1 . \mathrm{LCI}_{\mathrm{vent}}$ and $\mathrm{LCI}_{\mathrm{ds}}$ were weakly correlated in controls $(\mathrm{R}=0.36, \mathrm{p}<0.01)$, moderately correlated in patients with asthma $(\mathrm{R}=0.51, \mathrm{p}<0.0001)$, and strongly correlated in patients with $\mathrm{CF}(\mathrm{R}=0.89, \mathrm{p}<0.0001)$. $\mathrm{LCI}_{\mathrm{ds}}$ was significantly raised in CF patients with chronic $P$. aeruginosa colonisation compared to those without chronic colonisation $(1.49$ vs $1.34, \mathrm{p}=0.004)$. LCI, $\mathrm{LCI}_{\text {vent }}$ and $\mathrm{LCI}_{\mathrm{ds}}$ were significantly raised in $\mathrm{CF}$ patients with a severe genotype compared to those with a mild genotype. No significant differences were observed between any of the asthma sub-phenotypes (severe vs non-severe, poorly-controlled vs not poorly controlled, exacerbator vs non-exacerbator, and eosinophilic vs noneosinophilic) with respect to any MBW parameter. The intraclass correlation coefficients of $\mathrm{LCI}_{\mathrm{vent}}$ and $\mathrm{LCI}_{\mathrm{ds}}$ exceeded 0.85 in the asthma and CF groups, and 0.60 in controls.

Conclusion The novel parameters $\mathrm{LCI}_{\mathrm{vent}}$ and $\mathrm{LCI}_{\mathrm{ds}}$ are repeatable and effectively discriminate between sub-phenotypes of CF, although their utility in asthma is currently unproven. Further studies are required to determine their utility in other airway diseases such as chronic obstructive pulmonary disease, to investigate their role as outcome measures in clinical trials, and to delineate their structural correlates.
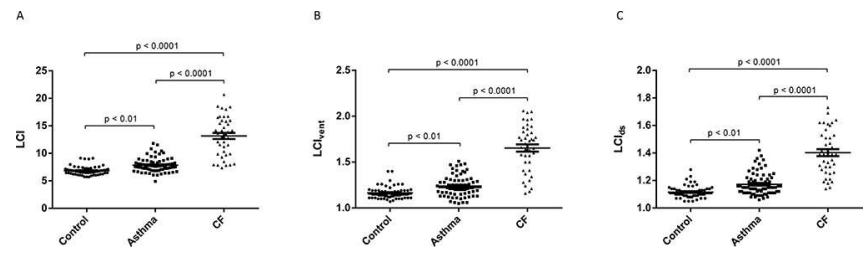

Abstract S45 Figure1 Multiple breath washout parameters across groups. Error bars denote mean $+/-$ standard error of the mean. Groups compared using one-way analysis of variance with Bonferroni correction

\section{Clinical studies in pulmonary vascular disease}

\section{S46 OUTCOME AFTER PULMONARY ENDARTERECTOMY (PEA): LONG TERM FOLLOW-UP OF THE UK NATIONAL COHORT}

J Cannon, K Page, M Roots, A Ponnaberanam, C Tracy, D Taboada Buasso, K Sheares, C Ng, J Dunning, S Tsui, J Pepke-Zaba, D Jenkins; Papworth Hospital, Cambridge, UK

\subsection{6/thoraxjnl-2013-204457.53}

Introduction Chronic thromboembolic pulmonary hypertension $(\mathrm{CTEPH})$ is a life threatening condition that historically has a poor outcome with supportive medical treatment. Pulmonary endarterectomy (PEA) is the treatment of choice and offers the 